Which Group to Credit (and Blame)? Whites Make Attributions about White-Minority Biracials' Successes and Failures Based on Their Own (Anti-)Egalitarianism and Ethnic Identification

\author{
Kaylene J. McClanahan \\ Northwestern University
}

Arnold K. Ho

University of Michigan

Nour S. Kteily

Northwestern University

[In Press at Group Processes and Intergroup Relations] 


\begin{abstract}
Individuals' perceptions of biracials can vary based on the motives of the perceiver. Here, we examine how two factors - perceivers' group-level identification motives and their system-level beliefs about the desirability of hierarchy (i.e., social dominance orientation)— predict the degree to which they attribute a biracial target's successes or failures to that target's White versus minority backgrounds. Across three studies examining different contexts, more anti-egalitarian White participants and (independently) more highly identified White participants rated a half-White, half-minority target as being shaped more by his minority ( $v s$. White) background when he was disreputable (vs. reputable), patterns broadly consistent with prior theorizing on the motivations to maintain social stratification and protect ingroup standing respectively. In direct contrast, however, egalitarian White participants and (independently) White participants low on ethnic identification credited a target's outgroup minority background when he was reputable (vs. disreputable), consistent with a desire to promote social equality and forgoing the opportunity to "bask in reflected glory" on behalf of the ingroup. Our results extend theorizing by underlining the benefits of jointly considering both group- and system-level motives when considering perceptions and attributions of individuals and groups, and by shedding new light on the understudied psychology of social egalitarians.
\end{abstract}




\section{Which Group to Credit (and Blame)? Whites Make Attributions about White-Minority Biracials' Successes and Failures Based on Their Own (Anti-)Egalitarianism and Ethnic Identification}

Consider a Black-White biracial winner of a Pulitzer prize. How might you attribute this person's success - was he shaped more by his Black background or his White background? How much are these attributions driven by his reputation-for example, would your attributions about the influence of the target's background change if instead of winning a Pulitzer prize, he'd been caught plagiarizing? Research on motivated social cognition suggests that the answer to such questions will be in the eye of the beholder (Kahan, 2013; Kunda, 1990; Noor, Kteily, Siem, \& Mazziotta, in press). That is, how we see this target will depend on our own characteristics as perceivers. In particular, existing research suggests that our perceptions will be influenced by factors such as our group membership and level of group identification: For example, a strongly identified White person might attribute this person's success (or failure) to his White or Black backgrounds differently than an individual who does not identify strongly as White. Less is known about the role of individuals' ideological beliefs about the desirability of hierarchy in this process. Beyond group identification, might individuals' perceptions of the target also be shaped by their hierarchy motives? That is, might individuals link a target's successes or failures to their background differently depending on the extent to which they are invested in seeing equality between social groups?

In this paper, we jointly consider the role of group and hierarchy motives in predicting attributions about a target's background. Specifically, we examine White Americans' attributions about a reputable or disreputable biracial target and investigate the extent to which their views are predicted by each of their social dominance orientation and their levels of group 
identification. Examining both group and hierarchy-relevant motives in concert is important given their theoretically distinguishable but potentially overlapping effects. For example, as we detail further below, it is possible that anti-egalitarian Whites might be driven to link the White ingroup with success and distance it from failure because of a group-based motive to maintain their ingroup's advantage, an ideological preference for maintaining social stratification between groups, or both.

Below, we briefly consider how each of these constructs might predict individuals' attributions about targets of mixed background depending on these targets' characteristics.

\section{Group Identification and the Categorization of Ambiguous Targets}

Humans derive much of their identity from the groups to which they belong (Tajfel \& Turner, 1986). It is therefore not surprising that we are motivated by the desire to affiliate with groups of high social standing. For example, prior work has shown that individuals are more likely to associate themselves with groups that are successful ("basking in reflected glory", or "BIRG") and distance themselves from groups that have failed ("cutting off reflected failure", or “CORF”; Cialdini et al., 1976; Snyder, Lassegard, \& Ford, 1986).

Our concern with maintaining the status of our group also influences our decisions about whom to allow into our groups. For example, individuals - particularly those who strongly identify with their group — engage in "ingroup overexclusion," setting more stringent requirements before including a target into their own group versus other groups, in order to ensure that their group is not "contaminated" (Castano, Paladino, Coull, \& Yzerbyt, 2002; Castano, Yzerbyt, Bourguignon, \& Seron, 2002). And in one clever demonstration closely related to the current work, Canadians were more likely to describe Benjamin Jones-a Jamaican-born Canadian runner - as Canadian after he set a world record, but as Jamaican after 
he was disqualified for doping (Stelzl, Janes, \& Seligman, 2008), suggesting that individuals used the status of an ambiguous target in order to determine whether or not they considered him to be a member of their group.

Another potential mechanism by which highly identified individuals can enhance or protect their group's standing is via the judgments they make about the responsibility the group deserves for the successes or failures of its members. That is, just as individuals might claim that a Jamaican-Canadian athlete is more Canadian when he wins than when he loses, they might also claim that a winning Jamaican-Canadian was more shaped by his Canadian background than a losing one. By tying a target's success to — or distancing a target's failure from-the ingroup background, highly identified individuals can associate their group with prestige or protect it from disrepute. In contrast, Whites who are low in ethnic identification are less attached to their group and likely to be less invested in protecting or raising its standing. For this reason, they should be less concerned about making attributions that favor the ingroup, and, at the limit, might even make attributions that favor the outgroup over the ingroup. Although such processes could apply quite broadly, they are particularly likely to be relevant for ambiguous targets (i.e., targets with a multi-racial/ethnic background). Indeed, for targets such as the Jamaican-Canadian runner or Black-White author, the relative contributions of their respective backgrounds to their successes and failures may be especially open to interpretation and contestation.

\section{Hierarchy and Social Dominance: A Distinct Ideological Factor in Attributions of Credit or}

\section{Blame?}

Whereas a great deal of research has focused on how group identification influences one's perceptions of others, another important but less-investigated factor-and a primary focus of our work —is one's attitude towards social hierarchy. In particular, we examine individuals' 
motivation to maintain or attenuate group-based hierarchies, a disposition captured by their social dominance orientation (i.e., SDO; Pratto et al., 1994; Ho et al., 2015). Importantly, although members of advantaged groups (e.g., Whites, men, high SES individuals) tend, on average, to be more supportive of inequality (i.e., higher in SDO) than members of disadvantaged groups, there is also substantial individual variability within groups (Sidanius \& Pratto, 1999). For example, despite belonging to the dominant racial group in society (and having access to the associated benefits), some proportion of Whites (i.e., those lower in SDO) are motivated to achieve equality between social groups.

Prior research has shown that higher levels of SDO are positively associated with a range of hierarchy-enhancing ideologies that subserve continued inequality. For example, individuals higher on SDO are more likely to hold stereotypes of minorities as unintelligent or lazy (Whitley, 1999), more likely to endorse ideologies that provide legitimacy to the low rank of those at the bottom (e.g., meritocracy, karma; Cotterill et al., 2014; Ho et al., 2015; Sidanius \& Pratto, 1999), and less likely to perceive the high levels of inequality in their environments that might warrant the egalitarian intervention they oppose (Kteily, Sheehy-Skeffington, \& Ho, 2017).

Just as individuals' social dominance orientation predicts the stereotypes they hold and the inequality they perceive, so should it influence judgments about who belongs in which groups within the hierarchy. Indeed, past research—largely focusing on the perspective of those higher in SDO — has suggested that social dominance motives predict the categorization of biracials in ways that help maintain group-based hierarchy. For example, Krosch et al. (2013) observed that individuals higher on SDO were more likely to categorize Black-White biracials as Black (i.e., hypodescent; Peery \& Bodenhausen, 2008; Ho et al., 2011), presumably as a means of maintaining the high-status of the advantaged White group by excluding individuals with 
(low-status) Black background. Ho et al. (2013) found that priming higher SDO Whites with realistic threat (i.e., the idea that Blacks posed a threat to White jobs, economic resources, etc.) accentuated the tendency to see Black-White biracials as Black, consistent with the idea that they use hypodescent as a way of protecting the hierarchical racial order. Finally, Kteily, Cotterill, Sidanius, Sheehy-Skeffington, and Bergh (2014) directly manipulated the standing of an ambiguous target, and observed that higher SDO Whites perceived the same racially ambiguous target as looking less White upon learning he was low (vs. high) in status (Kteily et al., 2014, Study 3). By keeping low ranking targets out of advantaged groups, higher SDO individuals can maintain the status of groups at the top, consistent with their preferences for hierarchymaintenance.

Although most of the work to date has focused on the perspective of those higher (rather than lower) on SDO, such biases are unlikely to be the exclusive purview of anti-egalitarian individuals (see also Lucas \& Kteily, in press). Because low SDO individuals favor hierarchyattenuation, they might be expected to make attributions about a target that promote the status of groups at the bottom of the hierarchy. Some preliminary findings support this idea. For example, Kteily et al. (2014, Study 3) found a nonsignificant trend consistent with the novel reasoning we present here: lower SDO Whites rated the high (vs. low) status ambiguous target as looking relatively more Black rather than more White. Whereas much existing work suggests that individuals seek to affiliate themselves and their groups with high status, this pattern suggests the possibility that individuals' system-level motivations for equality might lead them to associate disadvantaged outgroups with high status even when this forgoes an opportunity to claim status for the ingroup. Because research has largely focused on those striving to maintain or enhance 
the hierarchy, however, the psychology underlying the attributions of relatively egalitarian individuals remains understudied.

In short, we suggest that their system-level hierarchy motives may lead egalitarian and anti-egalitarian individuals to attribute the successes (and failures) of biracial individuals differently. For anti-egalitarians, attributing the success of biracial individuals to their higherstatus group membership is consistent with their desire to maintain the perceived superiority of the advantaged group. A similar logic applies when the target in question engages in disreputable behavior: anti-egalitarians would be likely to protect the standing of the privileged group by holding a biracial target's marginalized background responsible when he has done something bad. Conversely, we propose that egalitarian individuals should make the opposite attributions, attributing the successes - but not failures — of biracial individuals to their lower-status group membership. This pattern of attribution would align with egalitarians' desire to help raise the profile of the lower-status group, thereby promoting the greater social equality they favor. Additional factors linked to egalitarians' beliefs about the desirability of social equality might also contribute to this pattern of attribution. For example, because social egalitarians value diversity more than anti-egalitarians (Levin et al., 2012; Unzueta, Knowles, \& Ho, 2012), they may be more inclined to believe in and seek to convey the talents and capacities present among minority groups. Social egalitarians are also more internally motivated than anti-egalitarians to monitor and withhold prejudice (e.g., Webster, Burns, Pickering, \& Saucier, 2014), and might therefore be more cautious than anti-egalitarians about attributing a target's failures to his or her minority background.

\section{Two Routes to Attribution?}


Thus far, we have proposed that motivations at both the group- and system- levels should factor into the tendency to make attributions about the success or failure of biracial individuals. On the one hand, individuals' group-based motivations (i.e., group identification) should predict a tendency to maintain and enhance their group's standing, ascribing credit to the ingroup and distancing it from blame. On the other hand, individuals' system-level motivations for (in)equality (i.e., SDO) should lead those who show a stronger preference for equality to ascribe credit to and withhold blame from disadvantaged groups whereas those who favor inequality should make the opposite attributions.

It is worth further considering how these group and system-level motivations might interface with one another. Research suggests that, for members of advantaged groups such as Whites, identification with the ingroup is positively but only moderately correlated $(r \sim .15-.30)$ with the ideological preference for social hierarchy (e.g., Morrison, Plaut, \& Ybarra, 2010; Thomsen et al., 2010), suggesting that despite the potential for overlap, these two motives might independently predict individuals' pattern of attributions. That is, a highly identified antiegalitarian White, for example, might attribute a White-Black biracial target's failures to the Black outgroup as an independent function of both her desire to protect her White ingroup and her desire to maintain hierarchical differentiation between groups in society. At the same time, and despite their theoretical distinctness, it is possible that the two sets of motives might affect one another. For example, all else equal, a highly egalitarian White individual's preference for equality should be associated with making attributions that protect or promote the disadvantaged outgroup, even if this comes at the expense of her advantaged ingroup. But to the extent that this highly egalitarian individual is also highly identified as White, it is possible that her ingroup identification - which we propose leads to attributions that protect or promote their (advantaged) 
ingroup — will blunt her likelihood of making attributions that favor the disadvantaged outgroup. By the same token, a strong egalitarian motivation might moderate any tendency rooted in group identification to make attributions that favor the ingroup over a disadvantaged outgroup.

We tested these ideas across three studies, examining how White Americans made attributions about the factors shaping the behavior of reputable versus disreputable targets of multiracial background (half-White/half-outgroup) as a function of their group identification and their beliefs in the desirability of group-based equality (i.e., their SDO). We examined how each of these two motives might uniquely interact with target reputability to predict individuals' attributions about the relative formativeness of targets' advantaged and disadvantaged backgrounds (i.e., testing each of (a) the interaction between SDO and target reputability and (b) the interaction between ethnic identification and reputability while statistically controlling for the other). Employing a full factorial design, we further considered whether there was any evidence for a 3-way interaction between SDO, ethnic identification, and target reputability on individuals' attributions (such that the 2-way interaction between SDO and reputability depended on levels of ethnic identification and/or the 2-way interaction between ethnic identification and reputability depended on levels of SDO).

We focus in our work on attributions about the extent to which targets had been shaped by their advantaged (White) or disadvantaged (outgroup) group background, whereas prior work has primarily examined target categorization (i.e., whether a target belongs more to the White or minority category). Although these two perceptions are likely related, they are nevertheless distinct in theoretically meaningful ways. For example, a highly egalitarian White perceiver considering a reputable Black-White biracial might seek to shed positive light on that target's Black background while also taking care to allow the target to identify with either the White or 
Black category. That is, whereas categorizing the reputable target as Black does link his or her accomplishments with the disadvantaged outgroup, it also runs the risk of excluding the target from the ingroup. In contrast, attributing credit to the disadvantaged outgroup achieves a similar effect without implying any exclusion. We therefore expected a more straightforward link between the motivations we posit and attributions of formativeness ( $v s$. categorization). Still, we assessed categorization in our studies for exploratory purposes, and report all results using this measure in the Supplemental Materials (and discuss them briefly in the general discussion).

\section{Study 1}

In Study 1, we used a cover story (described further below) to tell participants that we were interested in their judgments about a biracial target described in a newspaper article. We manipulated whether this target — who had both ingroup and minority outgroup backgroundswas reputable or disreputable. We then examined which background participants indicated as having shaped the target more as a function of their own group identification and social dominance motives.

Participants. We initially piloted this study with a sample of 327 participants, and later collected data from an additional 402 participants. Because the second sample was drawn from the same population and followed essentially the same methodology ${ }^{1}$ we present the results from these two samples together as one study (full results from each sample separately are available in Supplemental Materials).

\footnotetext{
${ }^{1}$ There was only one methodological difference between these two samples. In the first sample, participants were assigned to one of three conditions: reputable target, neutral target, and disreputable target. However, results from the first study showed that the neutral target was actually rated as having a positive (versus neutral) reputation (participants rated the target significantly above the midpoint of the scale; $t=9.20 p<.001$ ). Thus, although the patterns for the neutral target were as predicted (attributions falling between the reputable and disreputable target conditions), we decided in the second sample to assign people only to the two conditions of central interest: reputable versus disreputable target. The results presented here include only the 219 participants from the first sample that were assigned to these two conditions.
} 
621 participants on Amazon's Mechanical Turk (mTurk), a reliable platform for conducting empirical research (Buhrmester, Kwang, \& Gosling, 2011), completed this study. We were interested here in how individuals would perceive multiracial targets of both ingroup and outgroup backgrounds. Because the population of mTurk participants is predominantly White, we chose a target with one White parent and one Latino parent, and focused our analyses on White participants, who represented the majority of our sample (470 participants). 11 participants were excluded because they failed one of two attention checks (these attention checks were embedded within scales including other items and simply asked the participants to check a given number on the scale to indicate that they were paying attention). Thus, our final sample included 459 White participants $(M$ age $=35.90 ; S D=12.08 ; 54.9 \%$ female $)$.

Procedure and Measures. Participants first filled out demographic information (including gender and ethnicity). They then completed our measure of ethnic identification, by answering the following two questions: "How often do you think about yourself as a member of your ethnicity?" ( 1 = not at all; 7 = often $)$ and "How important is your ethnicity to your identity?" $(1=$ not at all; $7=$ very important; $r=.71, p<.001)$. Next, they completed the $\mathrm{SDO}_{7}$ scale, a 16-item measure assessing individuals' support for intergroup hierarchy and group-based anti-egalitarianism (i.e., $\mathrm{SDO}_{7}$ scale; Ho et al., 2015; sample item: "An ideal society requires some groups to be on top and others to be on the bottom"; $1=$ strongly disagree; $7=$ strongly agree; $\alpha=.94$ ). They subsequently completed filler personality measures (TIPI: Gosling, Rentfrow, \& Swann, 2003; Barsch Learning Style Inventory: Barsch, 1991).

Following these measures, participants read that they were part of a study designed to compare journalism students at Northwestern University with other Americans lacking journalism training in terms of their perception and interpretation of a news article. Consistent 
with this cover story, we asked participants two questions about any prior journalism education they might have received. Participants were subsequently told that they would be asked to read an article, come up with a headline for the article, and then answer questions relating to its content. In order to incentivize participants to pay attention to the article, we informed participants that whoever generated the best headline (as determined by the research team) would receive a $\$ 5$ bonus.

Participants then read a fictitious newspaper article (full text available in Supplemental Materials) about a biracial individual, within which we embedded our experimental manipulation of target reputation. Across conditions, participants read about Dr. Alex Mendez, who was born in Mexico to a father with a stereotypically Latino name (Juan Mendez) and an American mother with a stereotypically White name (Molly Thompson). Participants also read that Dr. Mendez had moved to Washington, DC at the age of two, and lived in the U.S. since. ${ }^{2}$ Participants learned that Dr. Mendez was a doctor at a George Washington University medical school who was working on developing a cure for melanoma. We manipulated his reputation by providing the following information: in the reputable condition, participants read that Dr. Mendez had discovered a cure for melanoma which had been very well-received by his peers. In the disreputable condition, participants read that Dr. Mendez had recently admitted to falsifying data that indicated he had discovered a cure for melanoma.

\footnotetext{
${ }^{2}$ Although this vignette (and the ones used in later studies) did not give any specific information as to the target's race so as to avoid calling participants' attention to our questions of interest, it was successful in presenting participants with a biracial target: Average categorization of the target (anchored on "Latino" and "White") was always generally around the (unlabeled) midpoint (4) of the scale, suggesting that, on average, people did see the target as being of mixed background (rather than as belonging to just one category). The same was true across all three studies (Ms ranging from 3.56-3.64; see Table 1). The two items assessing target categorization were: "Do you consider Alex more Latino or more White?" and "Does Alex give off the general impression of being more Latino or more White?" (in Studies 2 and 3 the second item was replaced with "To what extent would you categorize [Target] as more [Minority group] or White?" These items (about their respective targets) were highly correlated in all studies (Study 1: $r=.81, p<.001$, Study 2: $r=.94, p<.001$, Study 3: $r=.95, p<.001$ ).
} 
After participants read the article, they wrote a headline for the story and then answered several filler questions about the article (e.g., rating the quality of the writing and the articles' newsworthiness). ${ }^{3}$ Participants were then asked several questions about the target, purportedly to gauge the effectiveness of the "human element" in this piece of journalism. Several of these questions were also filler items (e.g., "How old did you the think the doctor in the story was?”). We also asked about the reputation of the target (i.e., "How high in status do you think Alex is?'), which served as a manipulation check.

Finally, we asked participants several questions to assess our central dependent variables. Of primary interest were participants' attributions about the relative formativeness of the group identities, or the extent to which the target was shaped by his White and Latino background. In order to assess this, we asked participants the following two items: "Which part of Alex's background do you think was more influential in making him who he is today?", and "Which part of Alex's background do you think was more formative?" on a scale from 1 (definitely Latino) to 7 (definitely White). These two items were averaged to comprise our scale of formativeness $(r=.66, p<.001) .{ }^{4}$ As an exploratory measure, we also included measures of target categorization. Results using this construct (for this and all studies) are available in the Supplemental Materials.

\section{Results}

The manipulation was successful in influencing target reputation, with participants rating the target in the reputable condition as having significantly higher standing than the target in the

\footnotetext{
${ }^{3}$ All materials for this and all other studies are available in the Supplemental Materials.

${ }^{4}$ In the second round of data collection, we included two additional items of formativeness. However, these items were not included in these analyses because participants from the first round did not have the opportunity to complete them. Results for the two- and four-item versions of the scale were very similar.
} 
disreputable condition (reputable: $M=5.77, S D=.86$; disreputable: $M=3.50, \mathrm{SD}=1.80 ; F(1$, 457) $=300.90, p<.001$, partial $\left.\eta^{2}=.40\right)$.

Our central interest was in examining whether participants' ratings of the formativeness of the ambiguous target's background were independently predicted by their own levels of SDO and ethnic identification as a function of the target's reputation (which were, consistent with prior work, modestly positively correlated; see Table 1). Thus, we were primarily interested in each of the SDO by condition and the ethnic identification by condition interactions (controlling for one another). However, we also considered the possibility of a three-way interaction between these variables, and we therefore tested the full factorial design. That is, centering SDO and ethnic identification, we regressed our formativeness variable on SDO, ethnic identification, and condition (which was dummy coded; $0=$ disreputable condition; $1=$ reputable condition), as well as the full set of interactions between these variables (SDO x condition, ethnic identification $\mathrm{x}$ condition, SDO $\mathrm{x}$ ethnic identification, and SDO $\mathrm{x}$ ethnic identification $\mathrm{x}$ condition). ${ }^{5}$

We observed no significant main effect of $\operatorname{SDO}(B=-.02, p=.71,95 \% \mathrm{CI}:-.13, .09)$ or condition $(B=-.05, p=.54,95 \% \mathrm{CI}:-.23, .12)$. There was a marginally significant main effect of ethnic identification $(B=-.06, p=.08,95 \% \mathrm{CI}:-.13, .01){ }^{6}$

We next turned to our key interaction analyses. The ethnic identification by condition interaction was significant $(B=.10, p=.050,95 \% \mathrm{CI}: .00, .21$; see Figure $1 \mathrm{~A})$. In each of our studies, we probed this interaction to explore the simple effects in each condition at low ethnic

\footnotetext{
${ }^{5}$ We also ran a similar model with just the interaction between SDO and condition (i.e., omitting ethnic identification), as well as a model with just the interaction between ethnic identification and condition (i.e., omitting SDO). The results of these models are available in the supplemental materials and are discussed briefly in the discussion section.

${ }^{6}$ We note that the main effects of the continuous variables (i.e., SDO and ethnic identification) in our models should be interpreted with care. Because we employed dummy coding for experimental condition (disreputable $=0$, reputable $=1$ ), the main effects of SDO and ethnic identification are correctly interpreted as the effect of these variables in the disreputable condition (see e.g., Judd, McClelland, \& Ryan, 2009).
} 
identification (1 SD below the mean) and high ethnic identification (1 SD above the mean). Examining these simple slopes, we observed that (controlling for their SDO) White individuals low on ethnic identification were marginally more likely to say the target was shaped by his Latino background when he was reputable than when he was disreputable $(B=-.23, p=.07,95 \%$ $\mathrm{CI}=-.48, .02)$. The effect of condition was not significant for participants at one SD above the mean of ethnic identification $(B=.12, p=.33,95 \% \mathrm{CI}:-.13, .37)$. Examining the interaction from the other perspective (i.e., examining the effect of identification within condition), we observed that low ethnic identifiers were marginally more likely than high identifiers to see the target's White background as more formative when he was disreputable $(B=-.06, p=.08, \mathrm{CI}=$ $.13, .01)$. There was not a significant effect of ethnic identification in the reputable condition ( $B$ $=.04, p=.296,95 \%$ CI: $-.04, .11)$.

We next turned to the interaction between condition and SDO, which we observed was significant $(B=.24, p=.002,95 \%$ CI: $.09, .39$; see Figure 1B). We again probed this interaction to explore the simple effects (examining effects at $+/-1 \mathrm{SD}$ around the mean on SDO). Controlling for ethnic identification, high SDO individuals were marginally more likely to say that the target's White group membership was more formative when he was reputable (vs. disreputable), $B=.22, p=.08,95 \% \mathrm{CI}$ - $-.03, .48$. In contrast, and consistent with our theorizing, egalitarian Whites (i.e., those $1 \mathrm{SD}$ below the mean on SDO) perceived the target's outgroup background as more formative when he was reputable (vs. disreputable), $B=-.33, p=.007,95 \%$ CI: $-.58,-.08$. Investigating the simple slopes from the other perspective (i.e., examining the effect of SDO within condition), we observed that the effect of SDO on attributions of the target's background was significant in the reputable condition $(B=.22, p<.001,95 \% \mathrm{CI}$ : .11, .32): the lower the perceivers' level of SDO, the more they assigned credit to the reputable 
targets' Latino background. There was not a significant effect of SDO in the disreputable condition $(B=-.02, p=.71,95 \%$ CI: $-.13, .09)$.

The other remaining two-way interaction (SDO by ethnic identification) was significant $(B=-.08, p=.008,95 \% \mathrm{CI}:-.14,-.02)$, as was the three-way interaction between SDO, ethnic identification, and condition $(B=.11, p=.012,95 \% \mathrm{CI}: .02, .19)$. Investigating the simple slopes of this 3-way interaction (see Supplemental Figure 1) revealed that the it was primarily driven by the modulating effects of ethnic identification on Whites higher in SDO. At average levels of ethnic identification, high SDO Whites showed a marginal tendency to see the target as more shaped by his Whiteness when he was reputable (vs. disreputable). This tendency was eliminated among high SDO Whites low in ethnic identification, but was accentuated (and indeed highly significant) among high SDO Whites who were also more strongly identified as White.

In sum, we broadly observed support for our hypotheses. Controlling for their ethnic identification, individuals differed significantly in their attributions of an ambiguous target's background as a function of their own levels of egalitarianism and the target's reputation. In line with related prior work, we found that Whites higher on SDO tended to perceive that a target was particularly shaped by his minority background when he was disreputable (compared to when he was reputable). On the other hand, we observed the first clear evidence to date that group members might make attributions consistent with promoting the status of other marginalized groups relative to their ingroup: controlling for their ethnic identification, egalitarian Whiteswho support equalizing the standing of high- and low-status groups-were relatively more likely to ascribe an ambiguous target's successes to his outgroup (vs. ingroup) background. Because we controlled for ethnic identification, this pattern cannot merely be egalitarians disidentifying with their advantaged ingroup, highlighting a system-level motivation (for group-based equality) that 
operates beyond humans' general tendency to desire affiliating their groups with success and protecting their groups from failure (Cialdini et al., 1976; Snyder, Lassegard, \& Ford, 1986).

We also observed some (albeit less clear) evidence that Whites' levels of group identification interacted with the target's reputation to predict their attributions of formativeness even after controlling for the effects of SDO. In particular, Whites lower (but not higher) on ethnic identification were (marginally) more likely to attribute the reputable target's success to his outgroup (i.e., Latino) versus ingroup background, thereby forgoing the opportunity to claim status on behalf of their group.

Finally, this study's findings provided some preliminary evidence that— despite their unique contributions - social dominance orientation and group identification might also modulate one another's effects. In particular, we found that the tendency among anti-egalitarian Whites to attribute success to a target's White background was eliminated when they were relatively weakly identified but accentuated when they were relatively highly identified as White. We consider the robustness of the evidence for this three-way interaction by examining it again in each study, and discuss the overall pattern of evidence we observe in more detail in the discussion.

Given the novelty of these findings, we sought to replicate them in a second sample, featuring a different target and news context. 


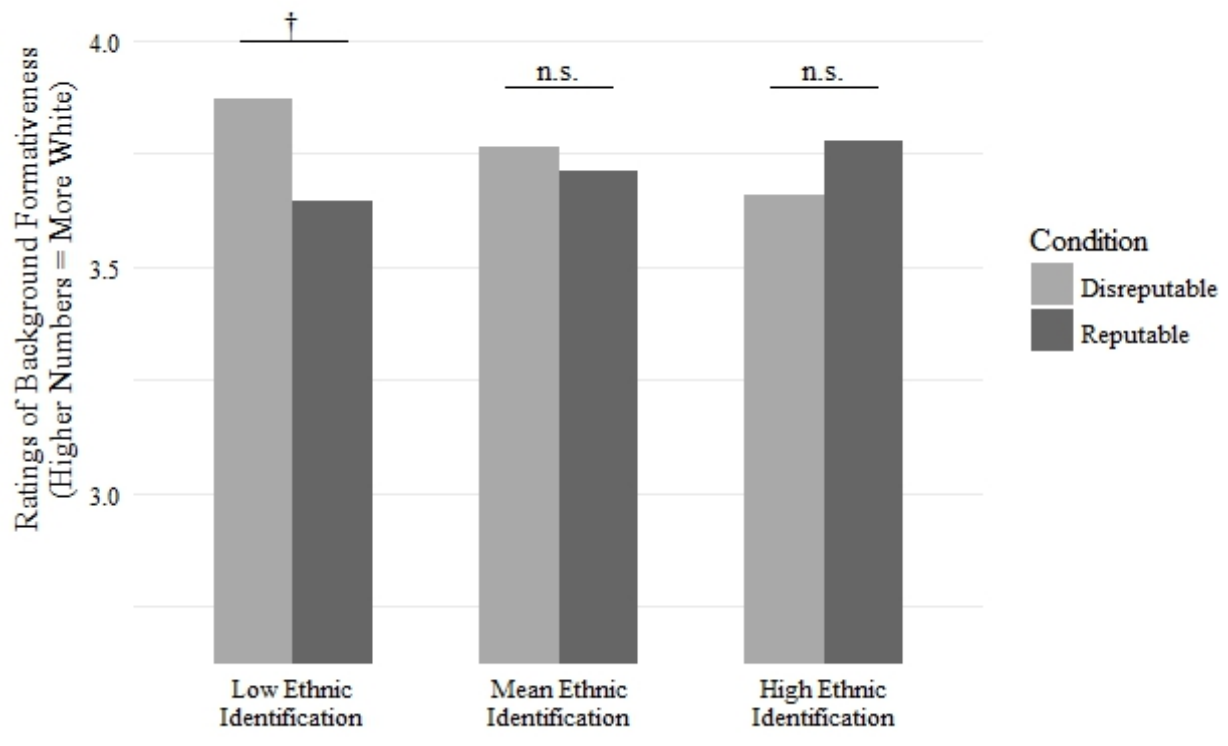

Figure 1A. Participants' ratings of the extent to which a biracial target was shaped by his respective group memberships as a function of target reputation and perceivers' ethnic identification in Study 1, controlling for social dominance orientation. $\uparrow p<.10$.

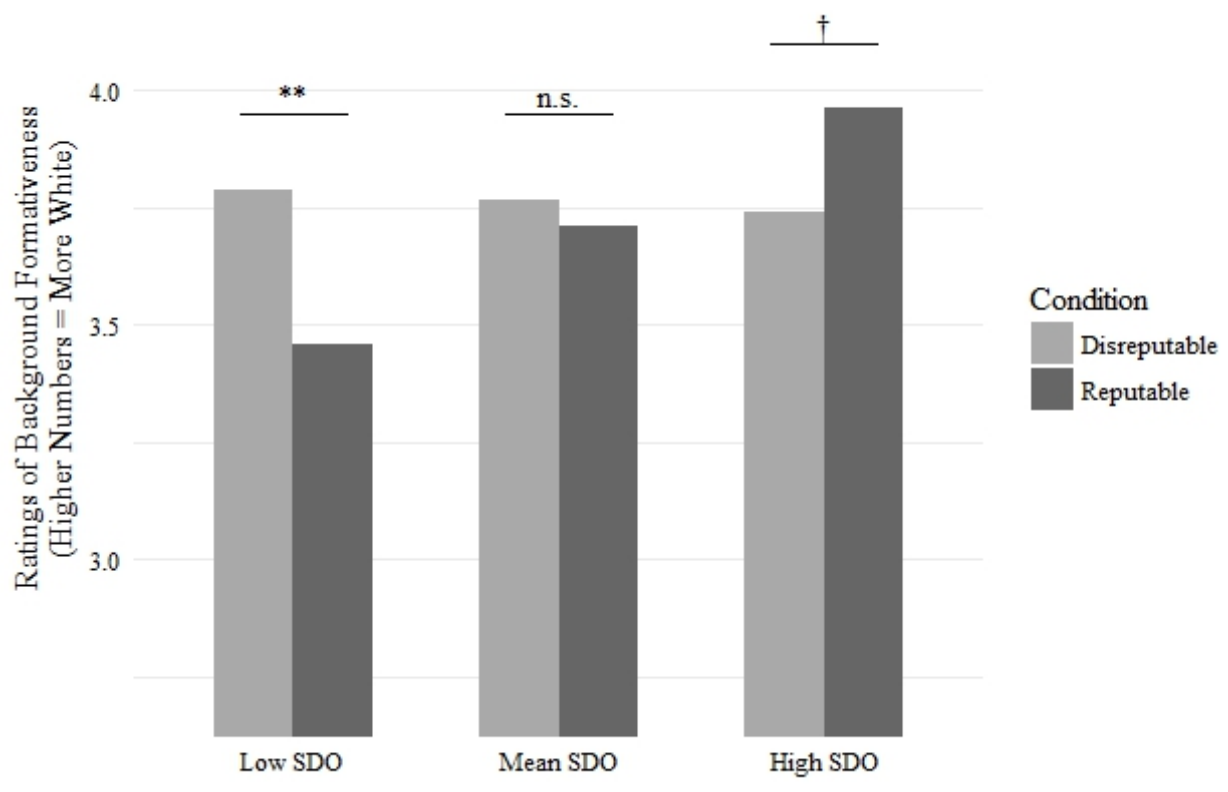

Figure 1B. Participants' ratings of the extent to which a biracial target was shaped by his respective group memberships as a function of target reputation and perceivers' social dominance motives in Study 1, controlling for ethnic identification. ${ }^{* *} p<.01+p<.10$ 


\section{Study 2}

In Study 2, we tested the robustness and generalizability of the effects from Study 1 by changing both the content of the purported news article in which the information about that target was embedded, as well as the target's minority outgroup. We tested our hypotheses by examining attributions about a half-White, half-Arab college student who either planned or prevented a school shooting.

\section{Method}

Participants. We sought to achieve a sample size similar to that of Study 1 . We thus recruited 501 participants from mTurk, of whom 411 participants were White. Seven of these participants were excluded from analyses because they failed to pass one of two attention checks, leaving a final sample of 404 White participants ( $M$ age $=39.56 ; S D=13.12 ; 41.83 \%$ female).

Procedure. Participants in Study 2 followed the same procedure as Study 1. However, participants read a different purported news story. In both conditions, participants read about a half-White, half-Arab target named Zack Yusef. He was living in the U.S. and the son of an Egyptian immigrant to the U.S. named Mustafa Yusef and his wife, Sandra Green. In the disreputable condition, participants read that Zack and his friend had been arrested for plotting a mass shooting on a university campus. In the reputable condition, participants read that Zack and his friend had prevented a school shooting by tackling an armed shooter on campus. Both stories featured Zack as the prominent character, implying the he was the impetus for both events. The full text of each news story is available in Supplemental Materials.

Ethnic identification and SDO were assessed as in Study 1 (ethnic identification: $r=.71$, $p<.001$; SDO: $\alpha=.94)$. Target reputation was measured by a single-item measure: "How high in status do you think Zack is?" The formativeness scale for this study included the two measures 
from the previous study in addition to two new items: "Which part of Zack's background do you think had a bigger impact on his identity?", and "Which part of Zack's background do you think most shaped who he is today?" Both these items were answered on the same 1 (definitely Arab) to 7 (definitely White) scale $(\alpha=.93)$.

\section{Results}

As in Study 1, our manipulation of target reputation was successful (reputable condition: $M=4.61, S D=1.08 ;$ disreputable condition: $M=2.87, \mathrm{SD}=1.29 ; F(1,401)=217.7, p<.001$, partial $\left.\eta^{2}=.35\right)$. We followed the same analytic approach as in Study 1, regressing formativeness attributions on the dummy-coded condition variable, SDO, ethnic identification and the interactions amongst these variables.

We observed a marginally significant main effect for $\operatorname{SDO}(B=-.12, p=.052,95 \% \mathrm{CI}$ : $.23, .00)$ and a significant main effect for ethnic identification $(B=-.20, p<.001,95 \% \mathrm{CI}:-.28,-$ $.11)$. There was also a significant main effect of condition, $(B=.34, p=.001,95 \% \mathrm{CI}: .14, .53)$, with participants in the disreputable condition tending, on average, to see the target as more shaped by his Arab background compared to participants in the reputable condition. The twoway interaction between SDO and ethnic identification was not significant $(B=-.03, p=.32$, 95\% CI: $-.09, .03)$.

Next, we turned to our focal interaction analyses. We observed a significant interaction between ethnic identification and condition $(B=.25, p<.001,95 \% \mathrm{CI}: .14, .37$; see Figure $2 \mathrm{~A})$. Examining the effects of condition at levels of ethnic identification, we found a significant positive effect of condition at one SD above the mean on ethnic identification, with high ethnic identifiers seeing the target's minority background as more formative when he was disreputable than when he was reputable $(B=.78, p<.001,95 \% \mathrm{CI}: .49,1.06)$. There was no significant 
effect of target condition at $1 \mathrm{SD}$ below the mean of ethnic identification $(B=-.10, p=.47,95 \%$ CI: $-.39, .18)$. Examining the effects of ethnic identification within each condition, we observed no significant effect in the reputable condition $(B=.06, p=.16,95 \% \mathrm{CI}:-.02, .14)$. There was, however, a significant effect in the disreputable condition $(B=-.20, p<.001,95 \% \mathrm{CI}$ : -.28 , .11), with low identifiers being significantly more likely than high identifiers to see the target as being shaped by his White background when he was disreputable.

We also observed the predicted interaction between SDO and target reputation $(B=.18, p$ $=.027,95 \% \mathrm{CI}: .02, .34$; see Figure 2B). Examining the simple effects of condition across levels of SDO, we found a pattern similar to Study 1 for relatively anti-egalitarian participants: Specifically, participants higher on SDO perceived the target's outgroup background as more formative when he was disreputable ( $v$. reputable; $B=.57, p<.001,95 \% \mathrm{CI}:=.27, .86)$. There was no significant effect of condition for participants one $\mathrm{SD}$ below the mean of $\mathrm{SDO}(B=.11, p$ $=.45,95 \% \mathrm{CI}:-.18, .39)$. Examining the simple effects of SDO within condition, we did not observe a significant effect of SDO when the target was reputable $(B=.07, p=.24,95 \% \mathrm{CI}$ : $.05, .18)$, although the effect was in the expected direction. In the disreputable condition, there was a marginally significant effect of SDO such that higher levels of SDO were associated with a lower likelihood of attributing formativeness to the target's White background, $B=-.12, p=$ $.052,95 \%$ CI: $-.23, .00$. 


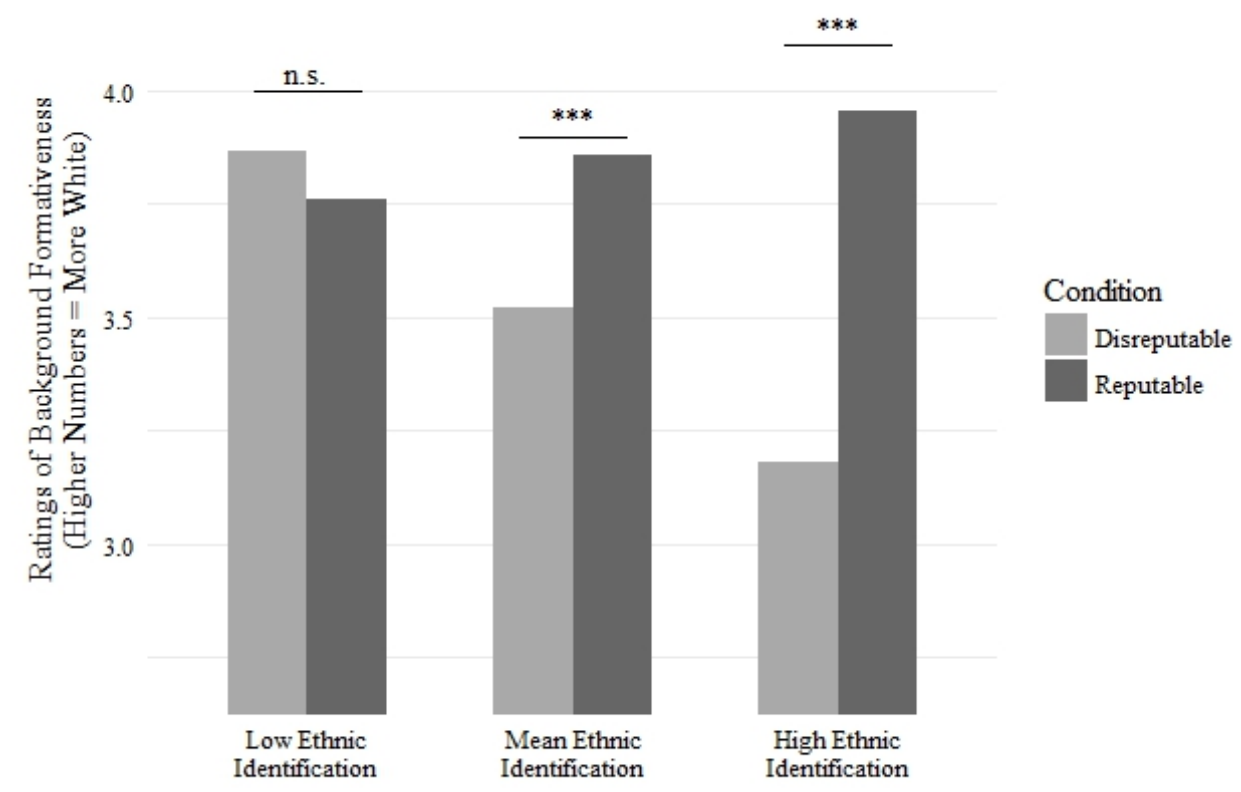

Figure 2A. Participants' ratings of the extent to which a biracial target was shaped by his respective group memberships as a function of target reputation and perceivers' ethnic identification in Study 2, controlling for social dominance orientation. $* * * p<.001$

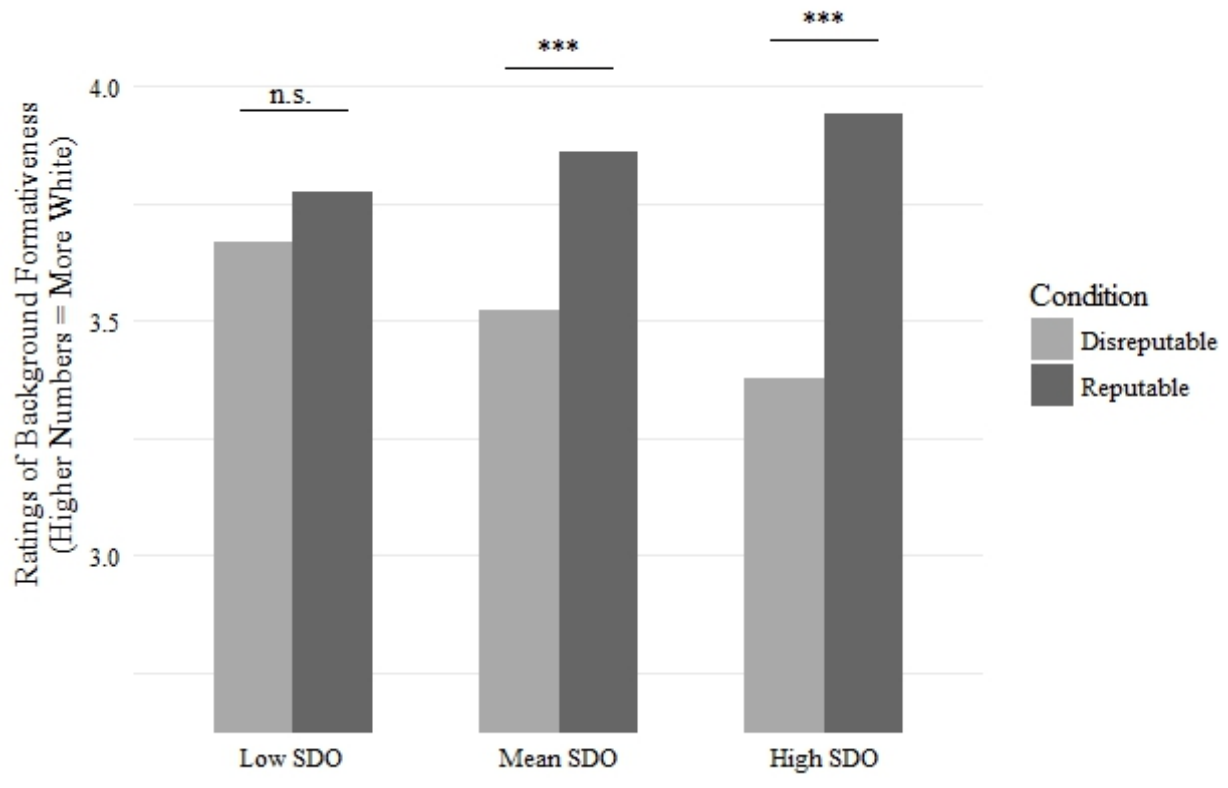

Figure 2B. Participants' ratings of the extent to which a biracial target was shaped by his respective group memberships as a function of target reputation and perceivers' social dominance orientation in Study 2, controlling for ethnic identification. $* * * p<.001$ 
Finally, and in contrast to Study 1, we observed no evidence for a three-way interaction between SDO, ethnic identification, and condition $(B=.02, p=.56,95 \% \mathrm{CI}:-.06, .10)$.

In sum, using a new context and a target with a different minority background, we again found evidence suggesting that attributions of the formativeness of a biracial target's background depended on his reputation and perceivers' levels of each of egalitarianism and group identification. The fact that the interactions between condition and each of egalitarianism and group identification held controlling for one another further highlights the distinct importance of both system and group-level motives. Of note, and unlike Study 1, we found little evidence here suggesting that levels of (anti-)egalitarianism and group identification modulated one another.

Similar to Study 1, we observed that individuals higher on SDO rated the target's Arab (vs. White ingroup) background as having been relatively more formative when he was disreputable ( $v$ s. reputable), an effect that held controlling for ethnic identification. Here, we did not see evidence for a significant effect of the target's reputation for individuals lower on SDO. Similarly, the interaction between ethnic identification and target reputation in this study appeared to be driven more by high White identifiers' tendency to blame the disreputable target's Arab background than low ethnic identifiers' tendency to credit the reputable target's Arab background. Although it is difficult to determine the precise reasons for this pattern, it may be a function of the widely-held stereotypes of Arab men being violent (e.g., Noor et al., in press; Saleem \& Anderson, 2013), which could have affected baseline views of the formativeness of the target's Arab background in the disreputable condition. Indeed, we observed a main effect of condition, such that participants were — on average - more likely to see the target as Arab in the disreputable ( $v s$. reputable) condition. Against this backdrop, it is notable that egalitarian and 
weakly identified Whites were not more likely to see Yusef's Arab background as formative when he was planning a violent attack ( $v s$. heroically preventing one).

\section{Study 3}

Studies 1 and 2 provide new evidence across two different contexts featuring targets with different minority outgroups that relatively egalitarian members of advantaged groups are more likely than relatively anti-egalitarian individuals to assign credit and blame in ways that help promote and protect the disadvantaged group. Despite generalizing our results to a new context and target groups, however, Study 2 also revealed a main effect of condition, whereby, on average, participants perceived the disreputable target (school shooter) as being shaped more by his Arab-ness. In order to further increase confidence in our results, we re-examined our ideas in a third context. Here, participants read about a reputable or disreputable half-White half-Black target who was described either as being an artist whose work was being celebrated at a new exhibit (reputable condition) or an artist arrested for art forgery (disreputable condition).

Participants. We again aimed for a large sample size comparable to Studies 1 and 2. Thus, we recruited 506 participants from mTurk, of whom 379 were White. Of these, 368 passed both attention checks, and thus constituted our final sample ( $M$ age $=38.80 ; S D=13.30 ; 55.7 \%$ female).

Procedure. Participants in Study 3 followed the same general procedure described in Studies 1 and 2. In this study, participants read about Jordan Sullivan, an artist from Los Angeles. Participants read that Jordan grew up with his mother, Tierra Jackson (i.e., a stereotypically Black name), in South L.A. until he was 6, and then moved to Portland to live with his father, Andrew Sullivan (i.e., a stereotypically White name). The article mentioned that Jordan's work depicted urban poverty and utilized graffiti techniques. In the reputable condition, 
participants read that Jordan's work had been critically acclaimed and was being featured at a new exhibit at a prestigious gallery. In the disreputable condition, participants read that Jordan's own work had not been particularly well-received, and that he had been arrested for fine art forgery.

SDO $(\alpha=.95)$, ethnic identification $(r=.77, p<.001)$, formativeness $(\alpha=.93)$, and our target reputation manipulation check were measured as in Study 2.

\section{Results}

As in the other studies, our manipulation of target reputation was successful (reputable condition: $M=4.32, S D=1.23$; disreputable condition: $M=2.84, S D=1.32 ; F(1,366)=124.4$, $p<.001$, partial $\eta^{2}=.25$.

We employed the same analytical strategy as in the prior studies, regressing attributions of formativeness on SDO, ethnic identification, condition, all two-way interactions, and the three-way interaction. We observed no significant main effect of ethnic identification $(B=.01, p$ $=.77,95 \%$ CI: $-.07, .10)$ or $\mathrm{SDO}(B=-.03, p=.60,95 \% \mathrm{CI}:-.15, .09)$ on formativeness judgments. There was a (unpredicted) significant main effect of condition, with participants, on average, seeing the target's Black background as more formative in the reputable condition than in the disreputable condition $(B=-.37, p=.001,95 \% \mathrm{CI}:-.59, .16)$. The two-way interaction between SDO and ethnic identification was not significant $(B=.04, p=.25,95 \% \mathrm{CI}$ : $-.02, .09)$ in this study.

Unlike prior studies, the ethnic identification by condition interaction was nonsignificant $(B=-.05, p=.42,95 \%$ CI: $-.17, .07$; see Figure $3 \mathrm{~A})$. There was not a significant effect of ethnic identification in either the reputable condition $(B=-.04, p=.41,95 \%$ CI: -.13 , $.05)$ or the disreputable condition $(B=.01, p=.77,95 \% \mathrm{CI}:-.07, .10)$. In line with the main 
effect of condition, there was a significant effect of condition for high identifiers $(B=-.46, p=$ $.003,95 \%$ CI: $-.77, .16$ ) in which high identifiers saw the target as more shaped by his Black background in the reputable ( $v s$. disreputable) condition. There was a similar but marginal effect of condition for low identifiers $(B=-.29, p=.065,95 \% \mathrm{CI}:-.59, .02)$

Consistent with prior studies, we again found evidence for the predicted SDO by condition interaction, $B=.17, p=.042,95 \% \mathrm{CI}: .01$, .33 (see Figure 3B).

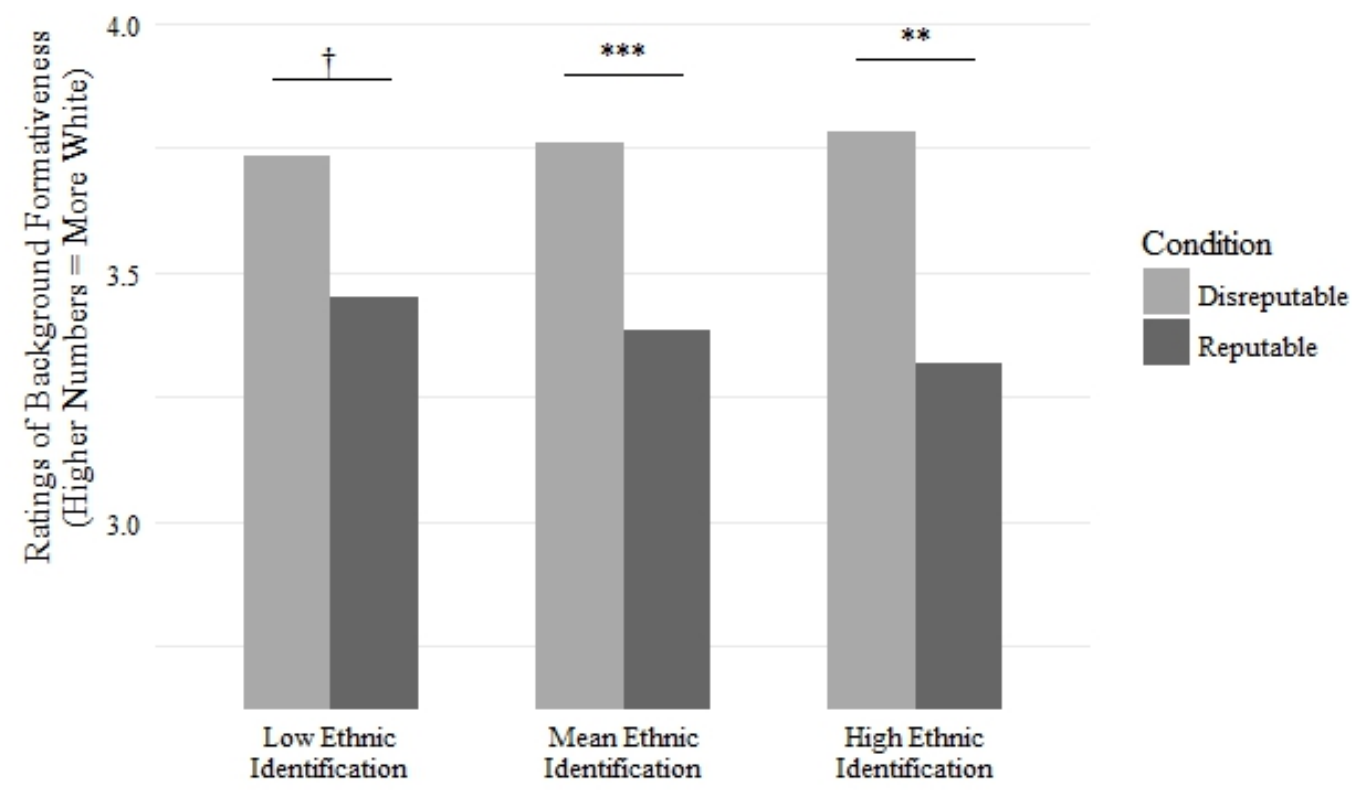

Figure 3A. Participants' ratings of the extent to which a biracial target was shaped by his respective group memberships as a function of target reputation and perceivers' ethnic identification in Study 3, controlling for social dominance orientation. $\uparrow p<.10 * * p<.01 * * * p$ $<.001$ 


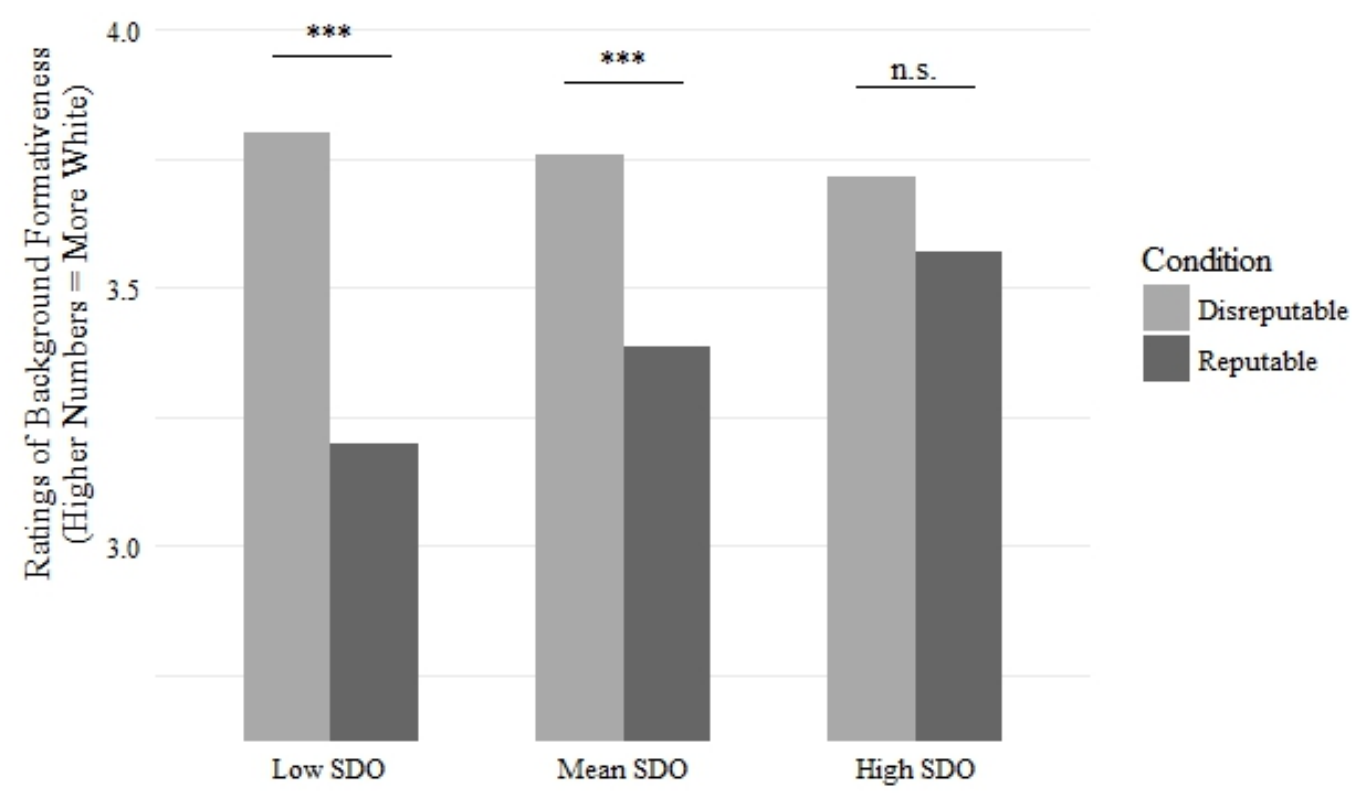

Figure 3B. Participants' ratings of the extent to which a biracial target was shaped by his respective group memberships as a function of target reputation and social dominance motives in Study 3, controlling for ethnic identification. *** $p<.001$

As in Studies 1 and 2, we again explored the simple effects of the SDO by condition interaction. Controlling for ethnic identification, we observed no significant effect of target reputation among Whites higher in SDO, $B=-.15, p=.35,95 \% \mathrm{CI}:-.46, .17$. In contrast, egalitarian Whites were significantly more likely to say that the target had been shaped by his Black background when he was reputable versus disreputable, $B=-.60, p<.001,95 \% \mathrm{CI}:-.90$, .30. The interaction appeared to be driven mostly by responses in the reputable condition: In this condition, egalitarian Whites rated Blackness as having been significantly more formative than higher SDO participants did, $B=.14, p=.018,95 \% \mathrm{CI}: .02, .26$. In contrast, levels of SDO did not significantly predict attributions of formativeness in the disreputable condition, $B=-.03, p=$ $.60,95 \%$ CI: $-.15, .09$. 
Here again (and as in Study 2), we found no evidence for a three-way interaction between SDO, ethnic identification, and condition $(B=-.04, p=.38,95 \% \mathrm{CI}:-.12, .05)$.

\section{Combined Samples}

Following the recommendation of Maner (2014), we examined our results across the three studies conducted. Specifically, because Studies 1-3 were very methodologically similar and utilized the same measures, we combined the data from the 1231 White Mturk participants in order to examine the results across all participants.

We conducted the same regression analyses as in Studies 1-3. There was no significant main effect of SDO $(B=-.05, p=.11,95 \% \mathrm{CI}:-.12, .01)$. We observed a significant main effect of ethnic identification on formativeness $(B=-.07, p=.002,95 \% \mathrm{CI}:-.12,-.03)$. There was no significant main effect of condition $(B=-.01, p=.90,95 \% \mathrm{CI}:-.12, .11)$. The two-way interaction between SDO and ethnic identification was not significant $(B=-.02, p=.25,95 \% \mathrm{CI}$ : $-.06, .01)$

As predicted, the effect of ethnic identification was qualified by a significant interaction with condition $(B=.09, p=.005,95 \% \mathrm{CI}: .03, .16$; see Figure 4A), controlling for SDO (and its interactions). Specifically, we observed that highly identified Whites were more likely to see the target as shaped by his minority background when he was disreputable than when he was reputable; this effect was marginally statistically significant $(B=.15, p=.059,95 \% \mathrm{CI}:-.01$, .32). In direct contrast, Whites low on ethnic identification were significantly more likely to see the target as shaped by his minority ( $v s$. White) background when he was reputable $(B=-.17, p=$ $.039,95 \%$ CI: $-.33,-.01)$. Examining the simple effects of ethnic identification (controlling for SDO) within each condition, there was no significant effect in the reputable condition $(B=.02, p$ $=.39,95 \% \mathrm{CI}:-.03, .07)$. There was, however, a significant effect in the disreputable condition 
( $B=-.07, p=.002,95 \% \mathrm{CI}:-.12,-.03)$, with high (vs. low) ethnic identifiers seeing the target as more shaped by his minority background when he was disreputable.

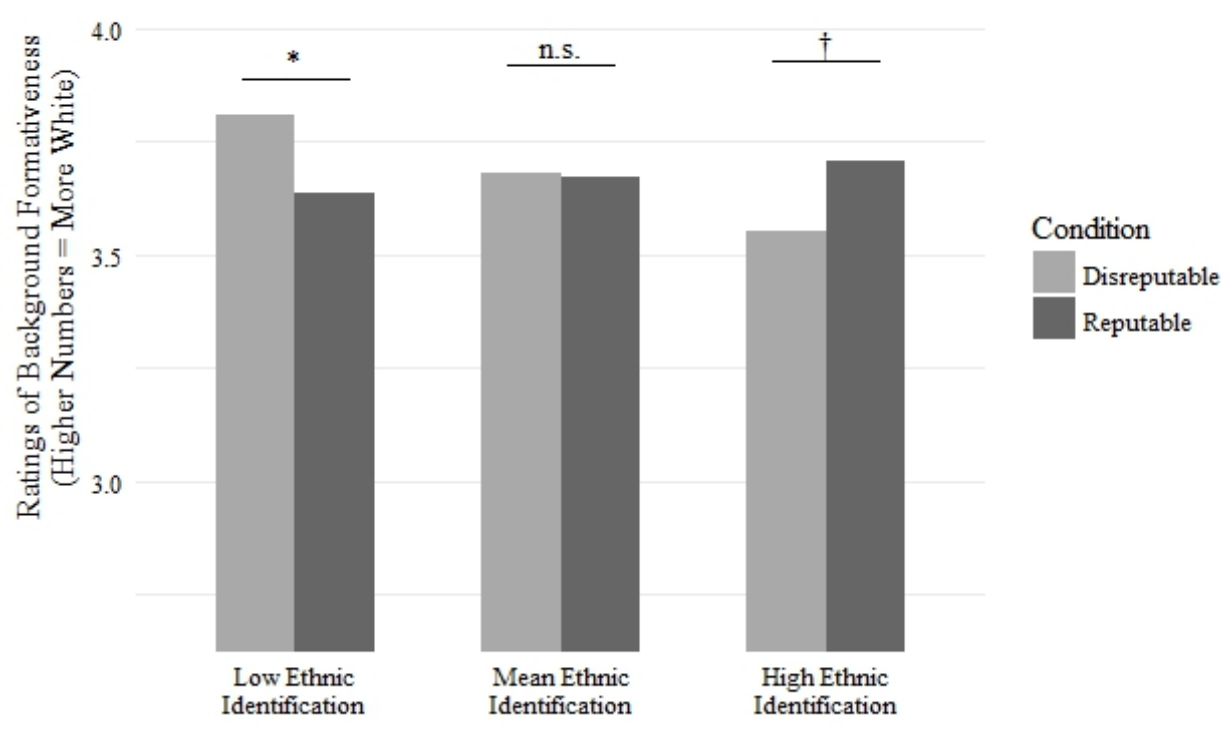

Figure 4A. Ratings of the extent to which participants saw a biracial target as having been shaped by his respective group memberships as a function of target reputation and perceivers' ethnic identification, controlling for social dominance orientation, combining across Studies 1-3. $+p<.10 * p<.05$

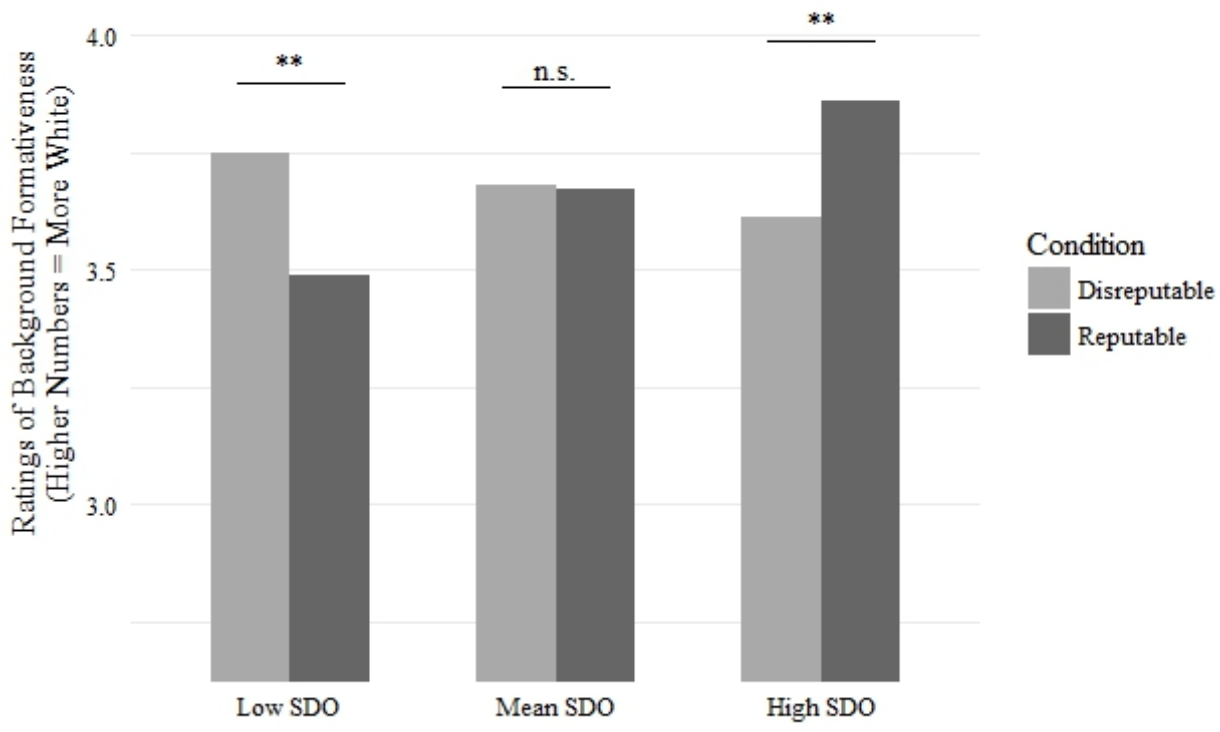


Figure 4B. Ratings of the extent to which participants saw a biracial target as having been shaped by his respective group memberships as a function of target reputation and perceivers' social dominance orientation, controlling for ethnic identification, combining across Studies 1-3. $* * p<.01$

The predicted interaction between condition and SDO was also significant, $B=.20, p<$ $.001,95 \%$ CI: .11, .30, controlling for ethnic identification (and its interactions) (see Figure 4B). In particular, participants high in SDO tended to see the target's minority background as being more formative when he was reputable ( $v s$. disreputable), $B=.25, p=.003,95 \% \mathrm{CI}$ : .08, .41. In direct contrast - and consistent with our novel theorizing - egalitarian Whites were significantly more likely to say that the target was shaped by his minority background when he was reputable (vs. disreputable), $B=-.26, p=.001,95 \% \mathrm{CI}:-.42,-.10$. Examining the simple effect of SDO within condition, we observed that lower levels of SDO were significantly associated with a higher likelihood of rating the target's minority background as formative in the reputable condition $(B=.15, p<.001,95 \% \mathrm{CI}: .08, .21)$. In contrast, in the disreputable condition, there was a (nonsignificant) trend such that higher levels of SDO were associated with a greater likelihood of saying the target was shaped by his minority background $(B=-.05, p=$ $.11,95 \%$ CI: $-.12, .01)$.

We observed no evidence of a significant three-way interaction between SDO, ethnic identification, and condition $(B=.02, p=.32,95 \%$ CI: -.02, .07; see Supplemental Figure 2).

\section{Discussion}

Across three studies, we find that judgments about the extent to which a biracial person is shaped by their respective racial backgrounds are influenced by features of both the target and the perceiver. Indeed, our results suggest the importance of both group and system-level motives, in ethnic identification and social dominance orientation (i.e., belief in the desirability of social 
hierarchy), respectively. Controlling for social dominance orientation (and its interactions), we observed that Whites higher and lower in ethnic identification differed in the attributions they made about which background had been more formative in shaping a half-White/half-minority target as a function of whether that target had a positive or negative reputation. In particular, consistent with existing research on the desire to maintain the standing of one's ingroup, avoid its 'contamination', and to bask in its successes while cutting off reflected failures (Castano et al., 2002; Cialdini et al., 1976; Snyder et al., 1986; Stelzl et al., 2008), highly identified Whites tended to see a target's White identity as more formative when he was reputable but his minority background as more formative when he was disreputable. Importantly, however, weakly identified Whites tended to show the exact opposite pattern, attributing targets' disreputable behavior to their Whiteness and reputable behavior to the minority outgroup. Our results therefore highlight an important (and theoretically grounded) boundary condition to existing research on group-based motives - in particular, psychological processes such as the concern to claim status for and avoid negativity on behalf of the ingroup may not apply (or even reverse) for weakly identified group members.

Beyond the effects of group identification, we independently observed similar (and more pronounced) patterns as a function of individuals' beliefs in the desirability of social hierarchy. We found that relatively anti-egalitarian Whites were more likely to claim that a target's minority background had been formative when he was disreputable ( $v s$. reputable). This accords with previous work in different but related domains, which has shown that individuals with higher levels of SDO are more likely to distance low status targets from dominant groups, thus maintaining the social stratification between groups at the top and those at the bottom that antiegalitarians favor (Ho et al., 2013; Ho, Kteily, \& Chen, 2017; Kteily et al., 2014; Krosch et al., 
2013). In contrast, we found that egalitarian Whites - who desire more equality between racial groups, despite their membership in an advantaged group —-were more likely to give a biracial's minority background credit when that target was reputable than when he was disreputable. We saw this pattern of attribution despite the fact that these egalitarian Whites were thereby forgoing opportunities to associate their own White ingroup with high status.

Our findings among those low on SDO are particularly noteworthy given the extent to which the psychology of social egalitarians remains understudied. Although some existing research has shown, for example, that they favor hierarchy-attenuating institutions and jobs (e.g., being public defenders; Pratto et al., 1994), no prior work has systematically examined how egalitarian motives might motivate perception of ambiguous targets. Our findings suggest the need to more broadly consider the ways in which social egalitarians - like anti-egalitariansmight also bring their unique motivations to bear on their perceptions of the world around them (see also Kteily et al., 2017; Lucas \& Kteily, in press). One intriguing pattern relevant to this point was our observation that, on average, egalitarian Whites tended to differ more from antiegalitarian Whites when it came to assigning credit for the biracial targets' successes ( $v s$. laying blame for his failures) (see Figure 4b). This asymmetry is worth further investigation - perhaps it reflects a particular willingness among egalitarian Whites to lift disadvantaged groups up (i.e., crediting them for successes) as compared to bringing down advantaged ones (i.e., blaming them for failures).

Our joint consideration of the impact of group and system-level motives is another notable contribution of our work. The vast majority of work examining the link between group identification or SDO and outcomes such as the categorization or punishment of multi-racial targets has examined these constructs separately (with one exception of which we are aware; 
Kteily et al., 2014). But despite the fact that they assess meaningfully distinct phenomena with plausibly independent effects, these constructs are positively correlated (as they were in our samples here; see Table 1), and it is possible that effects attributed to one construct examined in isolation might in fact have been due to its overlap with the other. For example, one could imagine that a highly identified anti-egalitarian White might attribute a disreputable biracial target's actions to his minority background because of either a desire to protect the standing of her White ingroup or the (correlated) desire to maintain hierarchical differentiation between groups or both. Without assessing both motives jointly, however, it is difficult to arbitrate between these possibilities.

Indeed, although our findings provided independent support for both routes, supplemental analyses also highlighted the importance of controlling for both motives. In particular, when we examined the interaction between ethnic identification and target condition without controlling for SDO (and its interaction with condition), we observed that the effects of ethnic identification appeared stronger than they were in our main models including these controls (see p. 20 of Supplemental Materials). For example, combining across studies, whereas the simple slopes for the effect of condition among low and high ethnic identifiers were close to the $95 \%$ significance boundary when controlling for SDO, they were clearly significant without controlling for SDO. And whereas the simple slope for the effect of ethnic identification in the reputable target condition was not significant controlling for $\operatorname{SDO}(p=.39)$, it was significant when we conducted the analysis without controlling for SDO $(p=.04)$. Similarly (albeit to a milder degree), SDO's effects were somewhat stronger when examined without controlling for ethnic identification (see p. 20 of Supplemental Materials). This suggests that research 
examining the effects of either ethnic identification or SDO without controlling for the other might be inflating the unique importance of each construct.

Beyond examining their potential overlap, we also considered whether levels of SDO and ethnic identification might moderate the effects of its counterpart (i.e., examining the 3-way interaction between SDO, ethnic identification, and target reputation on formativeness). For example, it is theoretically plausible that a highly identified but socially egalitarian White perceiver's ideological commitment to equality might impinge on their group-based motivation to attribute a target's successes to the White ingroup. Study 1 did provide support for a three-way interaction along these lines, but it was not significant in either of Studies 2 or 3, and was not robust when tested in our combined analysis using data across all three studies. Thus, our findings, taken together, provide more evidence for group identification and ideological support for hierarchy as two largely independent routes to attribution. Interestingly, however, when we nevertheless examined the simple effect patterns for the three-way interaction in our combined data, we did observe some intriguing patterns worth continued investigation (see Supplemental Figure 2). In particular, we noted that the tendency of low SDO Whites to credit the target's minority ( $v s$. White) background when he was reputable ( $v s$. disreputable) was significant at low and mean ethnic identification, but not at high ethnic identification. High SDO Whites credited the target's White (vs. minority) background when he was reputable (vs. disreputable) at mean and high levels of ethnic identification, but not at low ethnic identification. Similarly, weakly identified Whites were significantly more likely to credit the minority outgroup for successes at low and mean SDO, but not high SDO, and strongly identified Whites made the reverse attributions at mean and high SDO but not low SDO. Although the overall 3-way interaction was not robust, these simple effect patterns do suggest the need for continued examination of the 
hydraulic relationship between SDO and ethnic identification with respect to attributions about multiracial targets.

\section{Limitations and Future Directions}

Despite its contributions, our work also poses important questions that should be investigated further in future research. For one, although we intentionally attempted to vary the contexts and target backgrounds in the vignettes we used across studies, it will be important to further examine the generalizability of our findings using biracial targets (a) of other minority backgrounds (e.g., Asian, Native), (b) of female as well as male gender ${ }^{7}$, and (c) who derive their positive or negative reputation through different means than the ones we focused on here.

Indeed, in two of the studies, we observed main effects of target condition that we had not explicitly anticipated — in Study 2, participants were, on average, more likely to see the target's Arab (vs. White) background as formative when he was disreputable versus reputable (perhaps due to stereotypes of Arabs as violent) and in Study 3, participants were, on average, more likely to see the target's Black ( $v s$. White) background as formative when he was reputable versus disreputable (perhaps because urban art is stereotypically associated with Blackness and the art forgery the target engaged in in the disreputable condition - a white-collar crime- is stereotypically associated with Whites). The fact that the ethnic identification by condition interaction was significant in two of the three studies and the SDO by condition interaction was significant across all three studies provides confidence in the robustness of the results (as does

\footnotetext{
${ }^{7}$ The targets in our study were all male, and we therefore examined whether participant gender might have moderated our results (male perceivers share an additional category with the target). We found little evidence of consistent moderation as a function of gender. Gender significantly moderated the effects of SDO by Condition in Study 2 (with the effect of condition at high SDO stronger for men than women), but not in Studies 1 or 3 (nor in our combined data). Similarly, gender moderated the effects of Ethnic ID by Condition in Study 3 (with the effect of condition among weakly identified whites slightly stronger for men than for women), but not in Studies 1 or 2 (nor in our combined data). We also saw no evidence of gender moderating the 3-way interaction.
} 
the fact that these interactions were both clearly robust combining across studies). Still, the fact that there was a main effect of condition in Studies 2 and 3 means that even those average in SDO or ethnic identification showed an effect of condition, and thus, the simple effects of condition for those low and high on SDO (or ethnic ID) in those studies should be interpreted in comparison to this 'baseline' effect. For example, in Study 2, the fact that those low on SDO did not see the target's Arab background as more formative than his White background when he was disreputable (vs. reputable) should be interpreted against the fact that those at the average on SDO did. Similarly, in Study 3, the fact that those higher on SDO did not see the target's Black background as more formative than his White background when he was reputable (vs. disreputable) should be considered against the baseline tendency for those at the average on SDO to see the reputable target as more shaped by his Blackness. More work examining a broader set of vignettes, as well as employing control conditions in which the target has neutral status, will be helpful in continuing to better understand the patterns we highlight here. ${ }^{8}$

It would also be important to extend our examination to consider the perceptions of disadvantaged group members (e.g., Blacks). Here, we examined attributions of formativeness as a function of targets' reputation and perceivers' SDO and ethnic identification only among Whites, members of an advantaged group. Although we predict that high ethnic identifiers would

\footnotetext{
${ }^{8}$ As noted earlier, we originally attempted to employ a control condition in the vignette used for Study 1 , but observed that the target was nevertheless rated as having high status (see Supplemental details for more information). In order to begin exploring questions about how a neutral target might be perceived, we later conducted a post-test in which we presented 224 White participants with basic facts about the targets' background stripped of the focal reputable or disreputable actions he was said to have conducted in the key conditions of interest. Participants read about and rated - within-subjects and in randomized order - the targets from all three studies. The ratings of target status in these studies were as follows (Study 1: $M=4.92, S D=1.11$; Study 2: $M=$ 4.09, $S D=0.94$; Study 3: $M=4.05, S D=1.15$ ); the mean ratings of target formativeness were as follows (Study 1: $M=3.54, S D=1.06$; Study 2: $M=3.83, S D=1.11$; Study 3: $M=3.45, S D=1.06$ ). We did not analyze results with these data included, because doing so would have violated the logic of random assignment to condition. Moreover, participants rated all three targets and did so outside the context of the 'newspaper article' we employed for the main experimental conditions. Still, this post-test allowed us to get some sense of how participants rated the targets in terms of status and formativeness absent information about reputation.
} 
make group-serving attributions whether they belonged to advantaged or disadvantaged groups, the question of whether egalitarian members of disadvantaged groups would show the same pattern of attribution that we observed here among egalitarian Whites is worthy of future research. If egalitarian individuals' attributions are, as we reason, rooted in their desire to bring about group-based equality, we would expect that an egalitarian Black perceiver who is asked to judge the reasons for a Black-White target's success might credit the disadvantaged Black ingroup (rather than the White outgroup) because doing so would be consistent with the motivation to minimize the gap between those at the top and those at the bottom.

Beyond this, future work could more explicitly test the theorizing we put forward with regards to motivation. For example, we suggest that egalitarian Whites are more likely to credit the minority background of successful biracial targets in part because of their motivation to bring about group-based equality. Although the argument that beliefs about group-based equality can motivate attributions and perception is consistent with much prior theorizing and evidence (e.g., Ho et al., 2013; Kteily et al., 2014, 2017; Pratto et al., 1994), there are nevertheless alternative possible explanations. For example, it is possible that egalitarian individuals have more positive stereotypes than anti-egalitarians about members of disadvantaged groups, which lead them to conclude that a successful biracial target individual must have been shaped by their minority group membership. Although this idea is plausible, egalitarian Whites often saw reputable targets as shaped more by their minority ( $v s$. White) background. Thus, for this explanation to account for our effects, egalitarian Whites' stereotype of minority outgroup would have to be not only more positive than anti-egalitarian Whites' stereotype of minority outgroups, but also substantially more positive than egalitarian Whites' stereotype of their own group. Still, other possibilities could help to explain our results. Perhaps egalitarian Whites are less likely than anti- 
egalitarians to attribute a target's failures (vs. successes) to the outgroup ( $v s$. ingroup) not specifically because of a motivation to protect the standing and raise the profile of disadvantaged groups (in line with their desire for greater equality) but because they have a stronger motivation to avoid appearing prejudiced (Plant \& Devine, 1998; Webster et al., 2014), a possibility that future work could examine by assessing this construct. Social egalitarians are also known to value diversity (Levin et al., 2012; Unzueta et al., 2012), and saying that a reputable biracial target's minority background was formative might reflect egalitarians' personal belief and/or desire to highlight that successful individuals can be shaped by a diverse range of backgrounds (beyond just the dominant group). It is also quite possible that these potential routes could operate together to shape patterns of attribution.

Finally, our work calls for expanding the assessment of ambiguous person perception beyond pure categorization (which has been the dominant dependent variable in research on perceptions of ambiguous targets), by highlighting a factor that is relevant to the perception of biracial or ambiguous targets - the degree to which they are shaped by each of their outgroup backgrounds. Although perceiving a target as having been shaped by a given group should be positively correlated with perceiving them to belong to that group (and indeed, this was the case in our own data, $r \sim .65$; see Table 1 ), these perceptions are not one and the same, and the distinction between them may be important. In particular, attributions of formativeness may capture a pattern of crediting/blaming which is free from the inclusion/exclusion dynamics inherent in categorization. For example, by saying a successful biracial individual was heavily shaped by their minority outgroup, a White egalitarian can link the success of an ambiguous target to a disadvantaged outgroup without excluding him/her from the ingroup (as might be communicated if an egalitarian White said a successful half-White/half-minority target belonged 
to their minority group rather than being White). Consistent with the idea that attributions of formativeness are related to but distinct from categorization, when we explored how the results presented in this paper compared with similar analyses using categorization as an outcome (i.e., asking participants about the extent to which they saw the target as belonging to the minority or White groups; see Supplemental Materials for full details), we found patterns that were broadly similar to those we observed here but weaker. Combining across studies, the ethnic identification by condition interaction (controlling for SDO) was in the same direction as for formativeness, but not significant. The SDO by condition interaction on categorization was significant (as might have been predicted based on prior work; e.g., Ho et al., 2013; Kteily et al., 2014; Krosch et al., 2013), but the simple slopes for the effect of condition among those high and low on SDO were marginally significant. Moreover, consistent with the logic noted above, egalitarian Whites were more likely than anti-egalitarians to say that a reputable biracial target was shaped by his minority background, but they were not more likely to exclude him by saying that he didn't belong to the White category.

\section{Conclusion}

We provide evidence for a novel pattern of behavior in which, controlling for their ethnic identification, egalitarian (in contrast to anti-egalitarian) individuals attribute successes and failures of ambiguous targets in a way that could increase the standing of the low-status outgroup while forgoing opportunities to claim status for their own group. This pattern of results has several important implications for the study of the biracial individuals, expands our understanding of the interplay of group- and system-level motivations, and sheds new light onto the relatively understudied psychology of egalitarians. 


\section{References}

Barsch, J. (1991). Barsch learning style inventory. Academic Therapy Publications.

Buhrmester, M., Kwang, T., \& Gosling, S. D. (2011). Amazon's Mechanical Turk: A new source of inexpensive, yet high-quality, data? Perspectives on Psychological Science, 3, 3-5. http://doi.org/10.1177/1745691610393980

Castano, E., Paladino, M.-P., Coull, A., \& Yzerbyt, V. Y. (2002). Protecting the ingroup stereotype: Ingroup identification and the management of deviant ingroup members. The British Journal of Social Psychology, 41, 365-385. http://doi.org/10.1348/014466602760344269

Castano, E., Yzerbyt, V., Bourguignon, D., \& Seron, E. (2002). Who may enter? The impact of in-group identification on in-group/out-group categorization. Journal of Experimental Social Psychology, 38(3), 315-322. http://doi.org/10.1006/jesp.2001.1512

Cialdini, R. B., Borden, R. J., Thorne, A., Walker, M. R., Freeman, S., \& Sloan, L. R. (1976). Basking in reflected glory: Three (football) field studies. Journal of Personality and Social Psychology, 34, 366-375. http://doi.org/10.1037/0022-3514.34.3.366

Cotterill, S., Sidanius, J., Bhardwaj, A., \& Kumar, V. (2014). Ideological support for the Indian caste system: Social dominance orientation, right-wing authoritariamism and karma. Journal of Social and Political Pyschology, 2, 98-116.

Gosling, S. D., Rentfrow, P. J., \& Swann, W. B. (2003). A very brief measure of the Big-Five personality domains. Journal of Research in Personality, 37(6), 504-528. http://doi.org/10.1016/S0092-6566(03)00046-1

Ho, A. K., Sidanius, J., Cuddy, A. J. C., \& Banaji, M. R. (2013). Status boundary enforcement and the categorization of black-white biracials. Journal of Experimental Social Psychology, 
49(5), 940-943. http://doi.org/10.1016/j.jesp.2013.04.010

Ho, A. K., Sidanius, J., Kteily, N., Sheehy-Skeffington, J., Pratto, F., Henkel, K. E., ... Steward, A. L. (2015). The nature of social dominance orientation: Theorizing and measuring preferences for intergroup inequality using the new SDO7 scale. Journal of Personality and Social Psychology, 109 (6), 1003-1028.

Ho, A. K., Kteily, N., \& Chen, J. M. (2017). “You're one of us”: Black Americans' use of hypodescent and its association with egalitarianism. Journal of Personality and Social Psychology, 113, 753-768.

Ho, A. K., Sidanius, J., Levin, D. T., \& Banaji, M. R. (2011). Evidence for hypodescent and racial hierarchy in the categorization and perception of biracial individuals. Journal of Personality and Social Psychology, 100, 492-506.

Jost, J. T., \& Thompson, E. P. (2000). Group-based dominance and opposition to equality as independent predictors of self-esteem, ethnocentrism, and social policy attitudes among African Americans and European Americans. Journal of Experimental Social Psychology, 36, 209-232. http://doi.org/10.1006/jesp.1999.1403

Judd, C. M., McClelland, G. H., \& Ryan, C. S. (2009). Data analysis: A model comparison approach (2nd edition). New York, NY: Routledge Press.

Kahan, D. M. (2013). Ideology, motivated reasoning, and cognitive reflection. Judgment and Decision Making, 424, 407-424.

Krosch, A. R., Berntsen, L., Amodio, D. M., Jost, J. T., \& Van Bavel, J. J. (2013). On the ideology of hypodescent: Political conservatism predicts categorization of racially ambiguous faces as Black. Journal of Experimental Social Psychology, 49(6), 1196-1203. http://doi.org/10.1016/j.jesp.2013.05.009 
Kteily, N., Cotterill, S., Sidanius, J., Sheehy-Skeffington, J., \& Bergh, R. (2014). "Not One of Us": Predictors and consequences of denying ingroup characteristics to ambiguous targets. Personality and Social Psychology Bulletin. http://doi.org/10.1177/0146167214539708

Kteily, N., Ho, A. K., \& Sidanius, J. (2012). Hierarchy in the mind: The predictive power of social dominance orientation across social contexts and domains. Journal of Experimental Social Psychology, 48(2), 543-549. http://doi.org/10.1016/j.jesp.2011.11.007

Kteily, N. S., Sheehy-Skeffington, J., \& Ho, A. K. (2017). Hierarchy in the eye of the beholder: (Anti-)egalitarianism shapes perceived levels of social inequality. Journal of Personality and Social Psychology, 112(1), 136-159. http://doi.org/10.1037/pspp0000097

Kunda, Z. (1990). The case for motivated reasoning. Psychological Bulletin, 108, 480-498.

Levin, S., Matthews, M., Guimond, S., Sidanius, J., Pratto, F., Kteily, N. S., Pitpitan, E. V., \& Dover, T. (2012). Assimilation, multiculturialism, and colorblindness: Mediated and moderated relationships between social dominance orientation and prejudice. Journal of Experimental Social Psychology, 48 (1), 207-212.

Lucas, B., \& Kteily, N. S. (in press). (Anti-)Egalitarianism differentially predicts empathy for members of advantaged versus disadvantaged groups. Journal of Personality and Social Psychology.

Maner, J. K. (2014). Let's put our money where our mouth is: If authors are to change their ways, reivewers (and editors) must change with them. Perspectives on Psychological Science, 9, 343-351. http://doi.org/10.1177/1745691614528215

Morrison, K. R., Plaut, V. C., \& Ybarra, O. (2010). Predicting whether multiculturalism positively or negatively influences White Americans' intergroup attitudes: The role of ethnic identification. Personality and Social Psychology Bulletin, 36 (12), 1648-1661. 
Noor, M., Kteily, N. S., Siem, B., \& Mazziotta, A. (in press). "Terrorist" or "Mentally ill": Motivated biases rooted in partisanship shape attributions about violent actors. Social Psychologial and Personality Science.

Peery, D., \& Bodenhausen, G. V. (2008). Black + White = Black: Hypodescent in reflexive categorization of racially. Psychological Science, 19, 973-977.

Plant, E. A. \& Devine, P. G. (1998). Internal and external motivation to respond without prejudice. Journal of Personality and Social Psychology, 75, 811-832.

Pratto, F., Sidanius, J., Stallworth, L. M., \& Malle, B. F. (1994). Social dominance orientation: A personality variable predicting social and political attitudes. Journal of Personality and Social Psychology, 67(4), 741-763. http://doi.org/10.1037/0022-3514.67.4.741

Saleem, M. \& Anderson, C. A. (2013). Arabs as terrorists: Effects of stereotypes within violent contexts on attitudes, perceptions, and affect. Psychology of Violence, 3, 84-99.

Sidanius, J., \& Pratto, F. (1999). Social dominance: An intergroup theory of social hierarchy and oppression. Cambridge: Cambridge University Press.

Snyder, C. R., Lassegard, M., \& Ford, C. E. (1986). Distancing after group success and failure: Basking in reflected glory and cutting off reflected failure. Journal of Personality and Social Psychology, 51, 382-388. http://doi.org/10.1037/0022-3514.51.2.382

Stelzl, M., Janes, L., \& Seligman, C. (2008). Champ or chump: Strategic utilization of dual social identities of others. European Journal of Social Psychology, 38, 128-138. http://doi.org/10.1002/ejsp

Tajfel, H., \& Turner, J. C. (1986). The social identity theory of intergroup behaviour. In S. Worshel \& W. G. Austin (Eds.), Psychology of intergroup relations (pp. 7-24). Chicago: Nelson-Hall. 
Thomsen, L., Green, E. G. T., Ho, A. K., Levin, S., van Laar, C., Sinclair, S. \& Sidanius, J. (2010). Wolves in sheep's clothing: SDO asymmetrically predicts perceived ethnic victimization among White and Latino students across three years. Personality and Socila Psychology Bulletin, 36 (2), 225-238.

Unzueta, M. M., Knowles, E. D., \& Ho, G. C. (2012). Diversity is what you want it to be: How social-dominance motives affect construals of diversity. Psychological Science, 23(3), 303309.

Webster, R. J., Burns, M. D., Pickering, M., \& Saucier, D. A. (2014). The suppression and justification of prejudice as a function of political orientation. European Journal of Personality, 28, 44-59.

Whitley, B. E. . J. (1999). Right-wing authoritarianism, social dominance orientation, and prejudice. Journal of Personality and Social Psychology, 77(I), 126-134.

http://doi.org/10.1037/0022-3514.77.1.126 
Table 1. Descriptive Statistics and Variable Intercorrelations across Studies

\begin{tabular}{|c|c|c|c|c|c|c|c|}
\hline & \multirow{2}{*}{$\begin{array}{l}\text { N (high status } \\
\text { condition, low } \\
\text { status condition) }\end{array}$} & \multirow[t]{2}{*}{ Mean } & \multirow[t]{2}{*}{ SD } & \multicolumn{4}{|c|}{ Intercorrelations } \\
\hline & & & & Condition & SDO & $\begin{array}{c}\text { Ethnic } \\
\text { Identification }\end{array}$ & Formativeness \\
\hline Study 1 & $459(223,226)$ & & & & & & \\
\hline SDO & & 2.55 & 1.17 & .07 & & & \\
\hline Ethnic Identification & & 3.57 & 1.70 & .09 & $.29^{* * *}$ & & \\
\hline Formativeness & & 3.74 & .93 & .01 & .12 & .01 & \\
\hline Categorization & & 3.57 & 1.09 & .06 & -.02 & -.03 & $.54^{* * *}$ \\
\hline Study 2 & $404(218,186)$ & & & & & & \\
\hline SDO & & 2.68 & 1.27 & .00 & & & \\
\hline Ethnic Identification & & 3.65 & 1.73 & -.07 & $.20^{* * *}$ & & \\
\hline Formativeness & & 3.68 & 1.04 & $.17^{* * *}$ & -.05 & $-.11^{*}$ & \\
\hline Categorization & & 3.64 & 1.11 & .13 & -.13 & $-.20^{* * *}$ & $.69^{* * *}$ \\
\hline Study 3 & $368(179,189)$ & & & & & & \\
\hline SDO & & 2.56 & 1.32 & -.06 & & & \\
\hline Ethnic Identification & & 3.73 & 1.78 & -.04 & $.27^{* * *}$ & & \\
\hline Formativeness & & 3.58 & 1.02 & $-.20^{* * *}$ & .08 & .01 & \\
\hline Categorization & & 3.56 & 1.16 & $-.19^{* * *}$ & .02 & -.02 & $.71^{* * *}$ \\
\hline Combined Sample & $1231(630,601)$ & & & & & & \\
\hline SDO & & 2.60 & 1.25 & .01 & & & \\
\hline Ethnic Identification & & 3.65 & 1.74 & -.01 & $.25^{* * *}$ & & \\
\hline Formativeness & & 3.67 & 1.00 & .00 & $.05^{\dagger}$ & -.03 & \\
\hline Categorization & & 3.59 & 1.12 & .00 & -.04 & $-.08^{* *}$ & $.65^{* * *}$ \\
\hline
\end{tabular}

